\title{
Novel Porcine Model of Acute Severe Cardiogenic Shock Developed by Upper-Body Hypoxia
}

\author{
P. OSTADAL ${ }^{1}$, M. MLCEK ${ }^{2}$, S. STRUNINA ${ }^{3}$, M. HRACHOVINA ${ }^{2}$, A. KRUGER $^{1}$, \\ D. VONDRAKOVA ${ }^{1}$, M. JANOTKA ${ }^{1}$, P. HALA ${ }^{1}$, O. KITTNAR ${ }^{2}$, P. NEUZIL ${ }^{1}$ \\ ${ }^{1}$ Cardiovascular Center, Na Homolce Hospital, Prague, ${ }^{2}$ Department of Physiology, First Faculty \\ of Medicine, Charles University in Prague, Prague, ${ }^{3}$ Faculty of Biomedical Engineering, Czech \\ Technical University in Prague, Prague, Czech Republic
}

Received January 10, 2016

Accepted June 20, 2016

\begin{abstract}
Summary
Despite the urgent need for experimental research in the field of acute heart failure and, particularly cardiogenic shock, currently there are only limited options in large animal models enabling research using devices applied to human subjects. The majority of available models are either associated with an unacceptably high rate of acute mortality or are incapable of developing sufficient severity of acute heart failure. The objective of our research was to develop a novel large animal model of acute severe cardiogenic shock. Advanced left ventricular dysfunction was induced by global myocardial hypoxia by perfusing the upper body (including coronary arteries) with deoxygenated venous blood. The model was tested in 12 pigs: cardiogenic shock with signs of tissue hypoxia developed in all animals with no acute mortality. Cardiac output decreased from a mean $( \pm S D)$ of $6.61 \pm 1.14 \mathrm{l} / \mathrm{min}$ to $2.75 \pm 0.63 \mathrm{l} / \mathrm{min}$, stroke volume from $79.7 \pm 9.8 \mathrm{ml}$ to $25.3 \pm 7.8 \mathrm{ml}$ and left ventricular ejection fraction from $61.2 \pm 4.3 \%$ to $17.7 \pm 4.8 \%$ ( $P \leq 0.001$ for all comparisons). In conclusion, the porcine model of acute cardiogenic shock developed in the present study may provide a basis for studying severe left ventricular dysfunction, low cardiac output and hypotension in large animals. The global myocardial hypoxia responsible for the decrease in cardiac contractility was not associated with acute death in this model.
\end{abstract}

\section{Key words}

Acute heart failure - Animal model - Cardiogenic shock • Extracorporeal life support • Extracorporeal membrane oxygenation • Pig

\section{Corresponding author}

P. Ostadal, Cardiovascular Center, Na Homolce Hospital, Roentgenova 2, 15030 Prague 5, Czech Republic.

Fax: +420 257272974. E-mail: ostadal.petr@gmail.com

Recent advances in the development of minimally invasive mechanical cardiac or circulatory support systems for the treatment of acute severe or rapidly progressing cardiogenic shock have prompted the urgent need for relevant animal models in preclinical testing. However, currently available options in large animals (e.g. dogs, pigs, sheep), in which instrumentation used on humans can be applied, are significantly limited. To date, several methods to induce acute left ventricular (LV) dysfunction (e.g. coronary microsphere embolization, coronary ligation or coronary obstruction by angioplasty balloon inflation) have been described in these large animal species (Abarbanell et al. 2010, Dixon and Spinale 2009, Schmitto et al. 2011). Development of sufficient myocardial ischemia leading to cardiogenic shock (i.e. left anterior descending artery occlusion) is, however, associated with high acute mortality, reaching up to $70 \%$ due to the induction of refractory ventricular fibrillation (Franciosa et al. 1980, Smiseth et al. 1983). Reduction of ischemic time or smaller coronary artery obstruction does not produce sufficiently severe heart failure leading to the development of cardiogenic shock, and is frequently followed by rapid restoration of LV function (Lindal et al. 1986, Moainie et al. 2002, Schmitto et al. 2009, 2011, 2008). Currently, a large 
animal model of acute severe cardiogenic shock with reasonably low mortality is lacking. Accordingly, we recently induced acute cardiogenic shock by selective perfusion of the left anterior descending artery with deoxygenated venous blood in a porcine model (Ostadal et al. 2015); however, the extent of LV dysfunction achieved was highly dependent on the coronary anatomy. The aim of the present study was, therefore, to develop a fully predictable and reproducible large animal model of acute cardiogenic shock induced by coronary perfusion with deoxygenated blood with acceptably low mortality.

Animal model. Twelve female swine (Sus scrofa domestica, Large White $\mathrm{x}$ Landrace crossbreed), four to five months of age, with a mean body weight of $45 \mathrm{~kg}$ were used to develop the model. After a $24 \mathrm{~h}$ fasting, general anesthesia was induced by administration of midazolam (0.3 $\mathrm{mg} / \mathrm{kg}$ intramuscular) and ketamine hydrochloride $(15 \mathrm{mg} / \mathrm{kg}$ to $20 \mathrm{mg} / \mathrm{kg}$ intramuscular). Initial propofol and morphine boluses $(2 \mathrm{mg} / \mathrm{kg}$ intravenous [IV] and $0.1 \mathrm{mg} / \mathrm{kg}$ to $0.2 \mathrm{mg} / \mathrm{kg} \mathrm{IV}$, respectively) were administered, and the animals were orotracheally intubated. Continuous IV infusions of propofol $(8 \mathrm{mg} / \mathrm{kg} / \mathrm{h}$ to $10 \mathrm{mg} / \mathrm{kg} / \mathrm{h})$ and morphine $(0.1 \mathrm{mg} / \mathrm{kg} / \mathrm{h}$ to $0.2 \mathrm{mg} / \mathrm{kg} / \mathrm{h})$ were used to maintain anesthesia. The doses were adjusted according to physiological parameters, photoreaction, corneal and palpebral reflexes, lacrimation and spontaneous movement. Potassium chloride $(2 \mathrm{mEq} / \mathrm{kg})$, in conjunction with general anesthesia, was used to euthanize the animals at the conclusion of the experiment.

Bilateral femoral (arterial and venous), carotid and jugular approaches were used for multiple sheath insertions using the standard percutaneous Seldinger technique. An initial rapid IV infusion of $1000 \mathrm{ml}$ normal saline was administered after anesthesia induction, followed by a continuous IV drip at a rate of $100 \mathrm{ml} / \mathrm{h}$ to $500 \mathrm{ml} / \mathrm{h}$ to reach and maintain a mean right atrial pressure of $5 \mathrm{~mm} \mathrm{Hg}$ to $7 \mathrm{~mm} \mathrm{Hg}$. An unfractionated heparin bolus (100 U/kg IV) was administered after sheath placement, followed by a continuous IV infusion of $50 \mathrm{U} / \mathrm{kg} / \mathrm{h}$ to maintain an activated clotting time of $180 \mathrm{~s}$ to $250 \mathrm{~s}$. Values were monitored every hour using the Hemochron Junior Signature Plus Microcoagulation System (ITC, USA).

Ventilation was provided using a ventilator (Hamilton G5, Hamilton Medical AG, Switzerland) set to the INTELLiVENT - Adaptive Support Ventilation mode. The ventilator was set to maintain an oxygen saturation $\left(\mathrm{SpO}_{2}\right)$ of $95 \%$ to $99 \%$, and an end-tidal $\mathrm{CO}_{2}$ pressure of $4.8 \mathrm{kPa}$ to $5.6 \mathrm{kPa}$.

Veno-arterial extracorporeal membrane oxygenation (ECMO) circuit consisted of a Levitronix Centrimag (Thoratec, USA) or Maquet Rotaflow (Maquet, Germany) console and centrifugal pump, a tubing set (HMO 70000 Adult Microporous Membrane Oxygenator with Softline Coating [MAQUET Cardiopulmonary AG, Germany]) and a mechanical gas blender (Sechrist, USA). Cannulas (Maquet, Germany) were inserted percutaneously using the standard Seldinger technique into the femoral artery and vein. The venous inflow cannula (21 Fr or $23 \mathrm{Fr}$ ) was inserted into the right atrium (the tip position was verified using fluoroscopy), and the femoral arterial outflow cannula (15 Fr or 17 Fr) was inserted into the femoral artery. Blood gas parameters in the blood leaving the oxygenator were continuously monitored (CDI'M Blood Parameter Monitoring System 500, Terumo Cardiovascular Systems Corporation, USA). The oxygen/air flow was repeatedly adjusted to maintain a partial pressure of oxygen $\left(\mathrm{PaO}_{2}\right)$ and partial pressure of carbon dioxide $\left(\mathrm{PaCO}_{2}\right)$ in the ranges of $10 \mathrm{kPa}$ to $15 \mathrm{kPa}$, and $4.0 \mathrm{kPa}$ to $6.5 \mathrm{kPa}$, respectively. The extracorporeal blood flow (EBF) was set to $11 /$ min until the start of the experiment.

Vital function and hemodynamic monitoring. Arterial pressure was measured using standard invasive methods with fluid-filled pressure transducers (Truwave, Edwards Lifesciences, LLC, USA) through a pigtail catheter inserted into the aortic arch. A Swan-Ganz catheter was inserted via a femoral vein to the pulmonary artery. Electrocardiography, heart rate (HR), invasive blood pressures (aortic arch and central vein), pulse oximetry, capnometry and invasive central venous $\mathrm{SpO}_{2}$ were continuously monitored in all animals (Monitor Life Scope TR, Nihon Kohden, Japan; and Vigilance II, Edwards Lifesciences, USA). Brain and peripheral tissue oxygenation levels were measured using near-infrared spectroscopy (INVOS Cerebral/Somatic Oximeter, Somanetics, USA).

Pressure-volume (PV) analysis. PV conductance catheter (Scisense 7F VSL Pigtail, Transonic, USA) was inserted into the left ventricle from the left carotid artery through the aortic valve to monitor cardiac performance during cardiogenic shock induction and maintenance. Correct positioning was assessed radiographically by confirming 


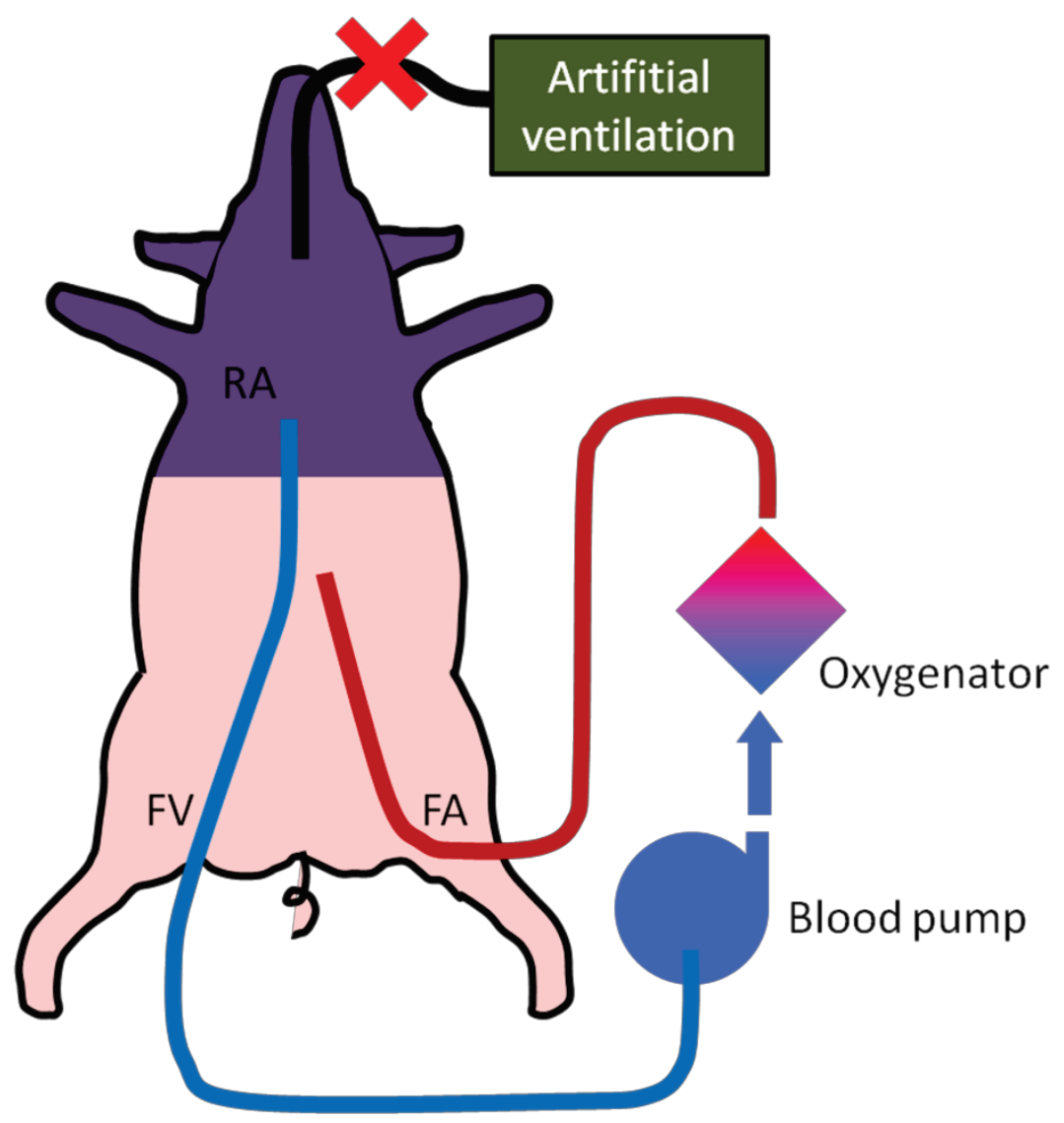

Fig. 1. Schematic illustration of the experimental settings. RA, right atrium; FA, femoral artery; FV, femoral vein

optimal PV loop morphology. The catheter was connected to the PV unit (Sciense ADV 500, Transonic, USA) and operated in admittance mode. The volume was calibrated against pulmonary thermodilution (Combo CCO catheter, Edwards Lifesciences, USA) at baseline. PV values were recorded continuously during the experiment. Collected PV data included end-diastolic pressure (EDP), end-diastolic volume (EDV), systolic blood pressure (SBP) and end-systolic volume (ESV). Stroke volume (SV) was calculated as $\mathrm{SV}=\mathrm{EDV}-\mathrm{ESV}$; left ventricular ejection fraction (LVEF) was calculated as $\mathrm{LVEF}=\mathrm{SV} / \mathrm{EDV}$; and cardiac output $(\mathrm{CO})$ was calculated as $\mathrm{CO}=\mathrm{SV} \times \mathrm{HR}$.

Cardiogenic shock development. After initiation of ECMO, the animals were stabilized for $10 \mathrm{~min}$. Artificial ventilation was subsequently switched to the CMV mode at 5 breaths/min, $100 \mathrm{ml}$ inspiration volume and a fraction of inspired oxygen $\left(\mathrm{FiO}_{2}\right)$ of 0.21 , which caused severe hypoxemia in the blood entering the left heart chambers and causing tissue hypoxia in all tissues perfused by LV cardiac output, i.e. upper (front) body including the coronary arteries, similarly to the clinical conditions known as "Harlequin syndrome" (Fig. 1). Subsequent global myocardial hypoxia rapidly lowered cardiac contractility, LVEF and blood pressure. At the same time, however, the lower body was perfused with fully oxygenated blood from ECMO entering the circulation via the femoral artery. During the hypoxic period, EBF was gradually increased to maintain a mean arterial pressure $>60 \mathrm{~mm} \mathrm{Hg}$, ensuring adequate perfusion pressure. With the increasing EBF and decreasing LV cardiac output resulting from impaired myocardial contractility (increased $\mathrm{EBF} / \mathrm{LV}$ cardiac output ratio) also substantially larger part of the body was perfused with oxygenated blood coming from ECMO. After approximately $1 \mathrm{~h}$ of myocardial hypoxia, the hemodynamic criteria for severe cardiogenic shock were met, including LVEF that decreased to $<30 \%$ and CO to $<3.5 \mathrm{l} / \mathrm{min}$. Thereafter, continuous heart perfusion with hypoxemic blood enabled the maintenance of advanced myocardial dysfunction and severely compromised hemodynamic parameters. If cardiac performance parameters decreased further with a risk of circulation collapse, the target level of cardiogenic shock severity was adjusted by a partial increase in ventilation.

Severe cardiogenic shock was successfully induced in all 12 animals, with no need for cardioversion/defibrillation and zero acute mortality. The achieved hemodynamic and cardiac performance values 
Table 1. Major hemodynamic and left ventricular performance parameters at baseline and after development of cardiogenic shock.

\begin{tabular}{lccc}
\hline Parameter & Baseline & Cardiogenic shock & P \\
\hline End-diastolic volume, $m l$ & $130.0 \pm 11.0$ & $142.0 \pm 13.3$ & 0.073 \\
End-systolic volume, $m l$ & $50.3 \pm 6.3$ & $116.6 \pm 11.9$ & $<0.001$ \\
Stroke volume, $m l$ & $79.7 \pm 9.8$ & $25.3 \pm 7.8$ & $<0.001$ \\
End-diastolic pressure, $m$ m Hg & $13.6 \pm 2.3$ & $28.1 \pm 5.8$ & $<0.001$ \\
Systolic pressure, mm Hg & $115.7 \pm 8.2$ & $63.5 \pm 22.2$ & $<0.001$ \\
Left ventricular ejection fraction, \% & $61.2 \pm 4.3$ & $17.7 \pm 4.8$ & $<0.001$ \\
Heart rate, beats/min & $82.8 \pm 9.8$ & $112.0 \pm 16.1$ & $<0.001$ \\
Cardiac output, l/min & $6.61 \pm 1.14$ & $2.75 \pm 0.63$ & 0.001 \\
\hline
\end{tabular}

Data presented as mean \pm SD unless otherwise indicated

at minimal ECMO flow (1 $1 / \mathrm{min})$ are shown in Table 1: CO decreased from $6.61 \pm 1.14 \mathrm{1} / \mathrm{min}$ to $2.75 \pm 0.63 \mathrm{l} / \mathrm{min}$, $\mathrm{SV}$ from $79.7 \pm 9.8 \mathrm{ml}$ to $25.3 \pm 7.8 \mathrm{ml}$, and $\mathrm{LVEF}$ from $61.2 \pm 4.3 \%$ to $17.7 \pm 4.8 \%$.

Our novel large animal model of acute severe cardiogenic shock has several limitations. First, ECMO initiation is required for the maintenance of adequate perfusion pressure and for perfusion of fully oxygenated blood to a substantial part of the body. This approach, however, afforded sufficient time for the induction of significant LV dysfunction. Moreover, LV ejections not only supply coronary arteries with hypoxemic blood, but, at least during the initial phases of a hypoxic period, other tissues, including the brain, as well, similarly to the circulatory conditions in "Harlequin syndrome"; therefore, cerebral damage could be anticipated. We cannot exclude the possibility that central nervous system hypoxia may have impaired some of the reflexes regulating blood circulation. Transient hypoxia of the upper body and continuing hypoxia in some tissues, i.e. right upper (front) limb, may also influence the circulatory conditions. This is one of the most important reasons why this model cannot be used generally for studying of all aspects and all etiologies of cardiogenic shock. Furthermore, although all animals subjected to global myocardial hypoxia in our study survived and none experienced ventricular fibrillation or sustained ventricular tachycardia, we cannot exclude the possibility that this observation was due to a limited sample size.

In conclusions, we developed a novel porcine model of acute cardiogenic shock with severe and sustained LV dysfunction, low $\mathrm{CO}$ and hypotension. Global myocardial hypoxia responsible for a decrease in cardiac contractility did not cause malignant arrhythmia(s) and all animals survived. With all limitations stated above this model can be used for the studying of selected aspects of cardiogenic shock and for the hemodynamic efficacy testing of some mechanical circulatory support systems.

\section{Conflict of Interest}

There is no conflict of interest.

\section{Acknowledgements}

This study was supported by an Institutional grant $\mathrm{MH}$ CZ - DRO (Nemocnice Na Homolce - NNH, 00023884) and by SVV266503/2013.

\section{References}

ABARBANELL AM, HERRMANN JL, WEIL BR, WANG Y, TAN J, MOBERLY SP, FIEGE JW, MELDRUM DR: Animal models of myocardial and vascular injury. J Surg Res 162: 239-249, 2010.

DIXON JA, SPINALE FG: Large animal models of heart failure: a critical link in the translation of basic science to clinical practice. Circ Heart Fail 2: 262-271, 2009.

FRANCIOSA JA, HECKEL R, LIMAS C, COHN JN: Progressive myocardial dysfunction associated with increased vascular resistance. Am J Physiol 239: H477-H482, 1980. 
LINDAL S, SMISETH OA, MJOS OD, MYKLEBUST R, JORGENSEN L: Reversible and irreversible changes in the dog heart during acute left ventricular failure due to experimental multifocal ischaemia. Acta Pathol Microbiol Immunol Scand A 94: 177-186, 1986.

MOAINIE SL, GORMAN JH, GUY TS, BOWEN FW, JACKSON BM, PLAPPERT T, NARULA N, ST JOHNSUTTON MG, NARULA J, EDMUNDS LH Jr, GORMAN RC: An ovine model of postinfarction dilated cardiomyopathy. Ann Thorac Surg 74: 753-760, 2002.

OSTADAL P, MLCEK M, KRUGER A, HALA P, LACKO S, MATES M, VONDRAKOVA D, SVOBODA T, HRACHOVINA M, JANOTKA M, PSOTOVA H, STRUNINA S, KITTNAR O, NEUZIL P: Increasing venoarterial extracorporeal membrane oxygenation flow negatively affects left ventricular performance in a porcine model of cardiogenic shock. J Transl Med 13: 266, 2015.

SCHMITTO JD, ORTMANN P, VORKAMP T, HEIDRICH F, KOLAT P, POPOV AF, DOERGE H, GROSSMANN M, SEIPELT R, RAMADORI G, SCHONDUBE AF: Histological changes in a model of chronic heart failure induced by multiple sequential coronary microembolization in sheep. J Cardiovasc Surg (Torino) 49: 533-537, 2008.

SCHMITTO JD, COSKUN KO, COSKUN ST, ORTMANN P, VORKAMP T, HEIDRICH F, SOSSALLA S, POPOV AF, TIRILOMIS T, HINZ J, HEUER J, QUINTEL M, CHEN FY, SCHONDUBE FA: Hemodynamic changes in a model of chronic heart failure induced by multiple sequential coronary microembolization in sheep. Artif Organs 33: 947-952, 2009.

SCHMITTO JD, MOKASHI SA, LEE LS, POPOV AF, COSKUN KO, SOSSALLA S, SOHNS C, BOLMAN RM, COHN LH, CHEN FY: Large animal models of chronic heart failure (CHF). J Surg Res 166: 131-137, 2011.

SMISETH OA, LINDAL S, MJOS OD, VIK-MO H, JORGENSEN L: Progression of myocardial damage following coronary microembolization in dogs. Acta Pathol Microbiol Immunol Scand A 91: 115-124, 1983. 